\title{
Effects of timolol and atenolol on benign essential tremor: placebo-controlled studies based on quantitative tremor recording
}

\author{
PER DIETR ICHSON A N E V A ESPEN \\ From the Department of Neurology, Ullevål Hospital, Oslo, Norway
}

S UMMARY Two different beta-adrenoreceptor antagonists, atenolol and timolol, were separately compared with a placebo in the suppression of essential tremor. In two-week single-blind placebo-controlled studies with cross-over, timolol (5 mg twice daily) and atenolol (100 mg once daily) produced an equal reduction in sitting heart rate and sitting blood pressure. Timolol was effective in reducing tremor while atenolol failed to reduce tremor amplitude. These results indicate that essential tremor can be reduced but not blocked, by the adrenergic blocker timolol with both $\beta 1$ and $\beta 2$ blocking properties; but not by the relatively selective $\beta 1$ blocking drug atenolol. Possibly, the tremor reduction is mediated by a peripheral effect on $\beta 2$ adrenoreceptors.

The use of propranolol is now an established method for reducing the amplitude of benign essential tremor. ${ }^{1-6}$ However, coexisting chronic obstructive bronchitis is not uncommon in patients with tremor and can prevent the use of this drug. Furthermore, hypotension can be a serious sideeffect of propranolol treatment. ${ }^{7}$ This makes it desirable to find out whether some other $\beta$-blockers have a different pattern of action and side-effects which could offer advantages in tremor therapy.

Timolol (Blocadren ${ }^{\circledR}$ ) is similar to propranolol and is an unselective $\beta$-blocker acting on both $\beta 1$ and $\beta 2$ adrenergic receptors, and it has no significant sympathomimetic activity. Satisfactory sympathetic block can be obtained from a single dose of $5-10 \mathrm{mg}$ of timolol as compared to $40-60 \mathrm{mg}$ of propanolol a day. In general, when two drugs have identical pharmacological effects, it is reasonable to choose the one which has the least undesirable side effects and can be given in the lower dosage. To our knowledge, the potential value of timolol in the treatment of patients with benign essential tremor, has not previously been assessed.

Atenolol (Tenormin ${ }^{\circledR}$ ) is a relatively selective $\beta 1$ adrenergic blocker which is less prone to cause bronchospasm than propranolol. However, a pre-

Address for reprint requests: Dr $\mathbf{P}$ Dietrichson, Department of Neurology, Ullevål Hospital, Oslo 1, Norway.

Accepted 16 June 1981 vious study ${ }^{8}$ based on clinical assessment reports, showed that the action of atenolol in reducing essential tremor was less effective than propranolol. In a clinical trial of the long term effects of $\beta$-adrenoceptor block after myocardial infarction, ${ }^{9}$ the opportunity was taken to measure changes in normal finger tremor using an accelerometer. It was found that propranolol produced a decrease in postural tremor, whereas the reduction produced by atenolol reached statistical significance only for right-hand action tremor and a left-hand post-action postural tremor. It might now be of interest to study the efficacy of atenolol treatment on benign essential tremor by a quantitative tremor recording technique. The present report deals with two quantitative studies on the tremor-reducing effects, one of oral timolol against a placebo and the other of oral atenolol against a placebo. Both studies were single-blind placebocontrolled studies of two weeks duration with cross-over.

\section{Methods}

The effects on tremor of (A) a period on timolol against a period on placebo and (B) a period on atenolol against a period on placebo were separately studied. The periods were of one week ( 7 days) each (fig 1).

In group (A) 20 outpatients (10 male, 10 female) 


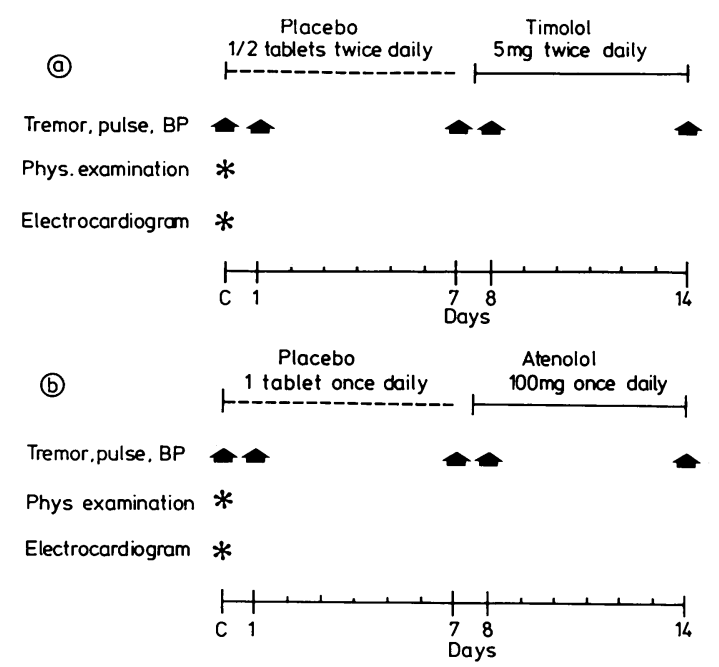

Fig 1 Design of the study on the effect on tremor by (a) timolol and (b) atenolol.

with a mean age of $55 \cdot 1$ years (range 26-73) and in group (B) 10 outpatients (4 male, 6 female) with a mean age of $50 \cdot 1$ years (range 23-66) were studied. The patients had benign essential tremor of varying intensity which made it difficult when drinking from a cup, doing up buttons and writing. The clinical diagnosis was also based on the presence of an increased postural tremor of the outstretched hands. The patients were told about the aims of the study and no patients selected refused to participate. The most tremulous hand was selected for examination. Prior to entry into the study, the patients were given a physical examination including an electrocardiogram which in all cases was normal (fig 1). Patients with obstructive lung disease or cardiac disorder were excluded.
The patients attended at the same time on five occasions (fig 1, arrows). Control assessment of the amount of tremor, the sitting blood pressure and the sitting pulse rate were performed in the tremor laboratory on the first day of the study (fig 1, C). Patients in group A, were given placebo from the evening of the control day until the morning of day 7 , and timolol from the evening of day 7 to the morning of day 14 (fig 1a). Patients in group $B$, were given placebo from the morning of day 1 to the morning of day 7 , and atenolol from the morning of day 8 to the morning of day 14 (fig $1 \mathrm{~b}$ ). All the patients were unaware of whether they received placebo or active medicament. The assessments were repeated on the first and the seventh day of each period. The patients' co-operation was controlled by counting the number of tablets remaining unused and by observing the depressant effects of the active drug on heart rate and blood pressure. Using these criteria, it appeared that all the patients took the tablets as prescribed.

The amount of tremor in the outstretched hand was detected by accelerometers mounted in a block (weight $20 \mathrm{~g}$ ) and strapped to the finger (fig 2). As a quantitative measure of the amount of tremor cannot be obtained directly from the accelerometer output because the tremor amplitude of the outstretched hand varies considerably even in the same individual in the three dimensions of space as well as from second to second in time, the signals were processed in an IBM 1800 digital computer. In group $A$, the transducers recorded the changes of acceleration of the outstretched hand in the $\mathrm{X}$ (horizontal direction) and the $\mathrm{Y}$ (vertical direction), and in group $\mathrm{B}$ in the $\mathrm{X}, \mathrm{Y}$ and $\mathrm{Z}$ (the antero direction indicated by a pointing movement) dimensions. The amount of tremor was expressed as the distance per second travelled by the transducer as a mean of 20 seconds in each dimension. The mode of signal processing has been described before ${ }^{10}$ and is briefly repeated in fig 3 . The tremor frequency was estimated by a fast Fourier transform programme. ${ }^{11}$

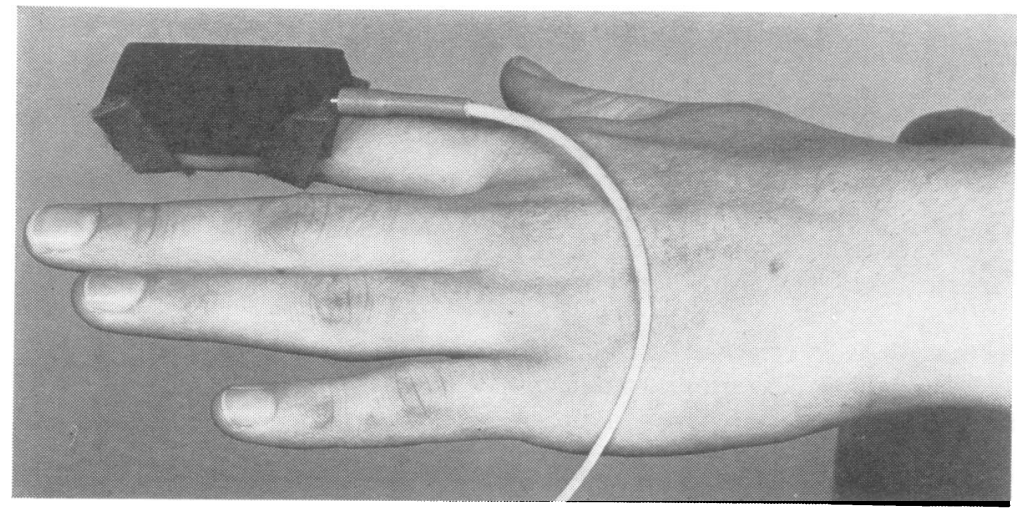

Fig 2 Transducer built for three-dimensional tremor recording. 

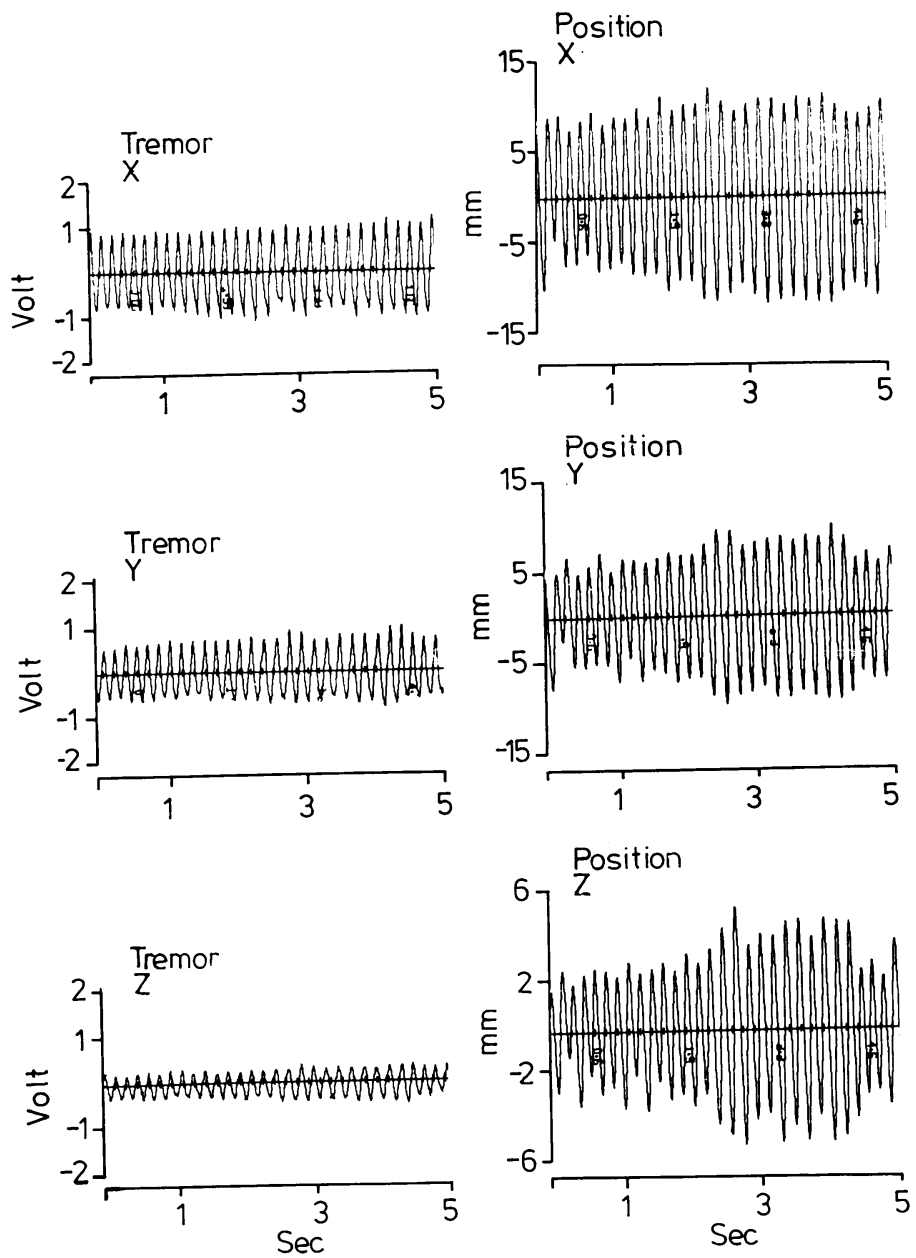

Fig 3 Signals from tremor recording in the $X, Y$ and $Z$ dimension are stored on an instrumentation tape recorder and then fed into a digital computer to checkthe proper reception of the accelerogram by the computer memory (left row). Quantitative tremor evaluation is performed by signal filtering $(<2,>20 \mathrm{~Hz})$, digitising and double integration whereby the position signal is obtained (middle row). The computer describes the total distance travelled by the transducer (right row) and giving the mean distance per sec, which is the wanted parameter (right row, arrow).

\section{Results}

The amount of tremor in each patient was assessed at five stages of the two weeks study (fig 1, arrows), then the values were mutually compared and the differences estimated by using the two-tailed Wilcoxon signed rank test. ${ }^{12}$ The main frequencies ranged between $5 \cdot 6-9.9 \mathrm{~Hz}$ and were unchanged during the study.

A Effect of timolol The main result was that timolol produced tremor reduction, estimated as the difference between measurements before and after active medication (table 1).

Control assessment-day 1: two doses of placebo did not result in any useful improvement. A placebo effect was shown as a moderate tremor reduction in the $\mathrm{Y}$-dimension $(\mathrm{p}<0.05)$ and a slight fall in systolic blood pressure $(p<0.05)$. Day $1-$ day 7: one week of placebo medication did not result in any further change either in tremor amount or in heart rate and blood pressure. Day 1 -day 8: a marked reduction in the amount of tremor $(\mathrm{p}<0.01)$ was caused by adding only two doses of timolol, each of $5 \mathrm{mg}$ to the placebo 
Table 1 Timolol vs placebo

\begin{tabular}{|c|c|c|c|c|c|}
\hline & \multicolumn{5}{|c|}{ Differences in } \\
\hline & \multirow[t]{2}{*}{ Dimension } & \multirow[t]{2}{*}{ Tremor } & \multirow[t]{2}{*}{ Pulse } & \multicolumn{2}{|c|}{ Blood pressure } \\
\hline & & & & Systolic & Diastolic \\
\hline Control-day 1 & $\begin{array}{l}\mathbf{X} \\
\mathbf{Y}\end{array}$ & $\begin{array}{l}\text { ns } \\
\mathrm{p}<0.05\end{array}$ & ns & $\mathrm{p}<0.05$ & ns \\
\hline Day 1- day 7 & $\begin{array}{l}\mathbf{X} \\
\mathbf{Y}\end{array}$ & ns & ns & ns & ns \\
\hline Day 1-day 8 & $\begin{array}{l}\mathbf{X} \\
\mathbf{Y}\end{array}$ & $\begin{array}{l}\mathrm{p}<0.01 \\
\mathrm{p}<0.01\end{array}$ & $p<0.01$ & $p<0.01$ & $\mathrm{p}<0.01$ \\
\hline Day 8-day 14 & $\begin{array}{l}\mathbf{X} \\
\mathbf{Y}\end{array}$ & ns & ns & ns & ns \\
\hline Day 7-day 14 & $\begin{array}{l}\mathbf{X} \\
\mathbf{Y}\end{array}$ & $\begin{array}{l}\text { ns } \\
\mathrm{p}<0.01\end{array}$ & $\mathrm{p}<0.01$ & $\mathrm{p}<0.01$ & $p<0.05$ \\
\hline
\end{tabular}

Two weeks single-blind placebo-controlled cross-over study. $\mathrm{n}=\mathbf{2 0}$.

medication of the previous week. The simultaneous fall in pulse rate and systolic and diastolic blood pressure $(\mathrm{p}<0.01)$ showed that the patient had taken the drug. Day 8-day 14: no further decrease in the amount of tremor, heart rate or blood pressure was observed when the timolol treatment was continued for another six days. Day 7-day 14: a similar depression of the amount of tremor by timolol medication was demonstrated by comparing the measurements taken on the last day on placebo with those taken on the last day of timolol medication. The Y-dimension values of the tremor, heart rate and systolic blood pressure, decreased markedly $(\mathrm{p}<0 \cdot 01)$, diastolic blood pressure fell slightly $(\mathrm{p}<0 \cdot 05)$. The small decrease

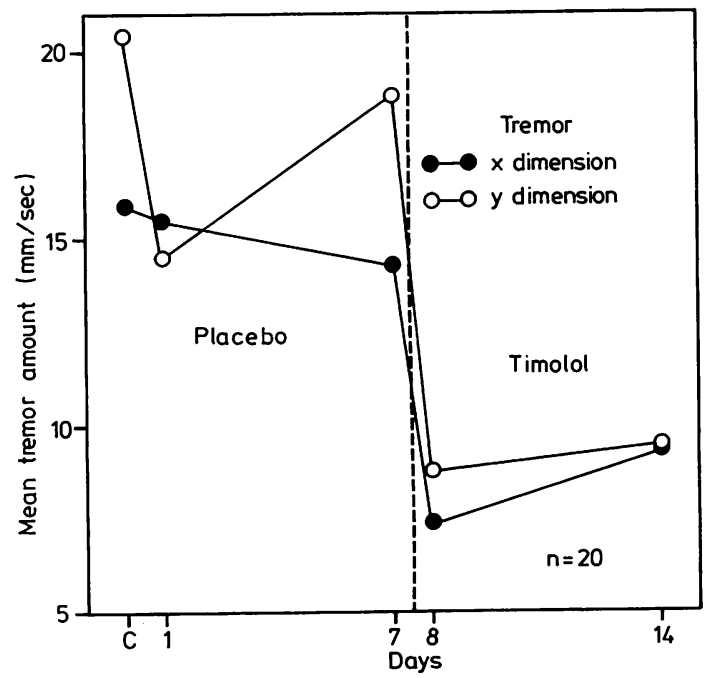

Fig 4 Reducing effect on mean tremor amount of timolol and non-significant effect of placebo. in the X-dimension value of the tremor was not statistically significant. The tremor reducing effect of timolol after one and after seven days of treatment, is shown in fig 4 . Patients with moderate tremor ( $<11 \mathrm{~mm}$ per second) showed the most uniform and useful effect (fig 5). A total suppression of the tremor was not obtained in any of the patients. Twelve of the 20 patients wanted to continue the timolol medication after the end of the study.

$B$ Effect of atenolol Atenolol did not reduce the amount of tremor, in spite of a satisfactory $\beta$ adrenergic block, as judged by the depressant effect on heart rate and blood pressure (table 2).

Control assessment-day 1: one dose of placebo 2 hours earlier on day 1 did not result in any change of the control values in tremor, heart rate or blood pressure. Day 1-day 7: one week of placebo consumption did not lead to any change

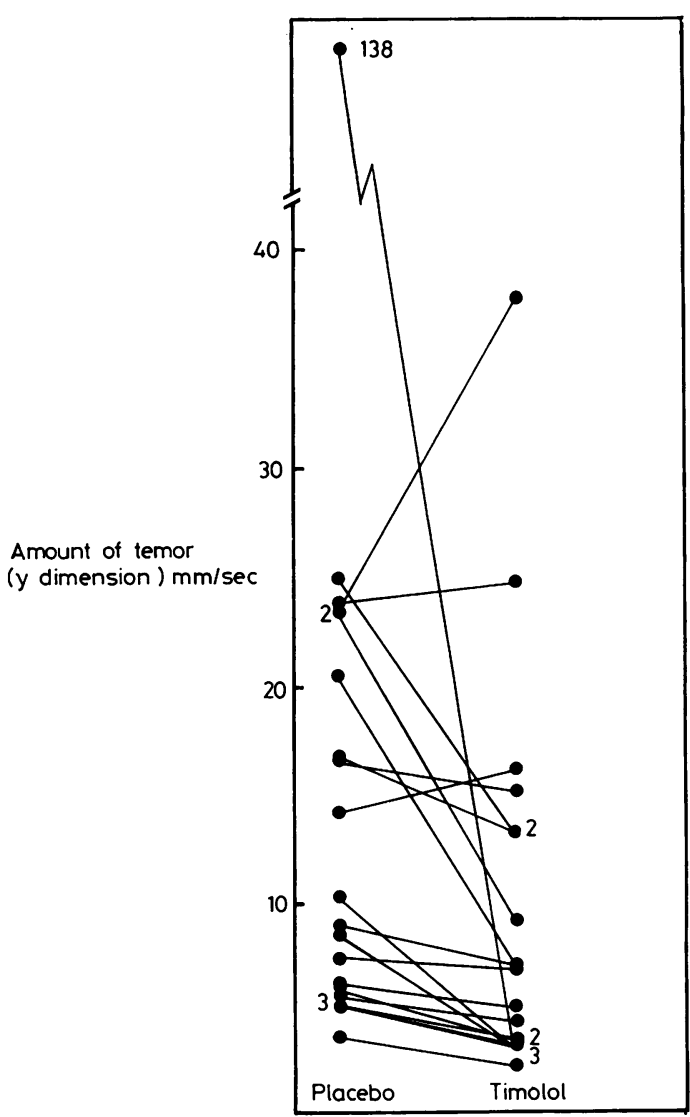

Fig 5 Individual effect on tremor amount by one week of timolol $5 \mathrm{mg}$ twice daily as compared to the effect of one week of placebo. 
Table 2 Atenolol vs placebo

\begin{tabular}{|c|c|c|c|c|c|}
\hline & \multicolumn{5}{|c|}{ Differences in } \\
\hline & \multirow[t]{2}{*}{ Dimension } & \multirow[t]{2}{*}{ Tremor } & \multirow[t]{2}{*}{ Pulse } & \multicolumn{2}{|c|}{ Blood pressure } \\
\hline & & & & Systolic & Diastolic \\
\hline \multirow[t]{2}{*}{ Control-day 1} & $\mathbf{X}$ & & & & \\
\hline & $\begin{array}{l}\mathbf{Y} \\
\mathbf{Z}\end{array}$ & ns & ns & ns & ns \\
\hline \multirow[t]{2}{*}{ Day 1-day 7} & $\mathbf{x}$ & & & & \\
\hline & $\begin{array}{l}\mathbf{Y} \\
\mathbf{Z}\end{array}$ & ns & ns & ns & ns \\
\hline \multirow[t]{2}{*}{ Day 1-day 8} & $\mathbf{X}$ & & & & \\
\hline & $\begin{array}{l}\mathbf{Y} \\
\mathbf{Z}\end{array}$ & ns & $\mathrm{p}<0.01$ & $p<0.02$ & $\mathrm{p}<0.02$ \\
\hline \multirow[t]{2}{*}{ Day 8-day 14} & $\mathbf{X}$ & & & & \\
\hline & $\begin{array}{l}\mathbf{Y} \\
\mathbf{Z}\end{array}$ & ns & ns & ns & ns \\
\hline \multirow[t]{2}{*}{ Day 7-day 14} & $\mathbf{X}$ & & & & \\
\hline & $\begin{array}{l}\mathbf{Y} \\
\mathbf{Z}\end{array}$ & ns & $\mathrm{p}<0.01$ & ns & $\mathrm{p}<0.01$ \\
\hline
\end{tabular}

Two weeks single-blind placebo-controlled cross-over study. $\mathbf{n}=\mathbf{1 0}$.

in tremor, heart rate or blood pressure. Day 1day 8: a marked reduction in heart rate $(p<0.01)$ and both systolic and diastolic blood pressure $(\mathrm{p}<0.02)$ demonstrated effective beta-adrenergic block of a single dose of $100 \mathrm{mg}$ atenolol given two hours before the assessment. However, no significant tremor depressing effect was recorded. Day 8-day 14: no further decrease in heart rate or blood pressure and no effect on tremor was observed when the atenolol treatment was continued for another six days. Day 7-day 14: a similar effect on heart rate $(\mathrm{p}<0.01)$ and diastolic blood pressure ( $\mathrm{p}<0.01$ ) was demonstrated by comparing the measurements from the last day on placebo with the last day on atenolol medication. However, one week on atenolol did not affect the tremor. The overall course of the study which is illustrated by mean tremor values (fig 6 ) shows a dip on the first day of atenolol treatment. This statistically insignificant mean decrease is apparent because the individual tremor values show no systematic trend: five increased and five decreased the tremor amount in response to one dose of $100 \mathrm{mg}$ atenolol (fig 7). Four of the 10 patients wanted to continue with atenolol after the end of the study as they felt a subjective improvement. Side effects No major side effects have been found either with timolol or with atenolol. Three of the 20 patients on timolol complained of vertigo, nausea or weakness of the legs as shown by a difficulty in climbing stairs. It is interesting that one patient complained of nightmares, a side effect which is claimed to be rare, as timolol penetrates the blood-brain barrier poorly. Four of the 10 patients on atenolol, complained of verti-

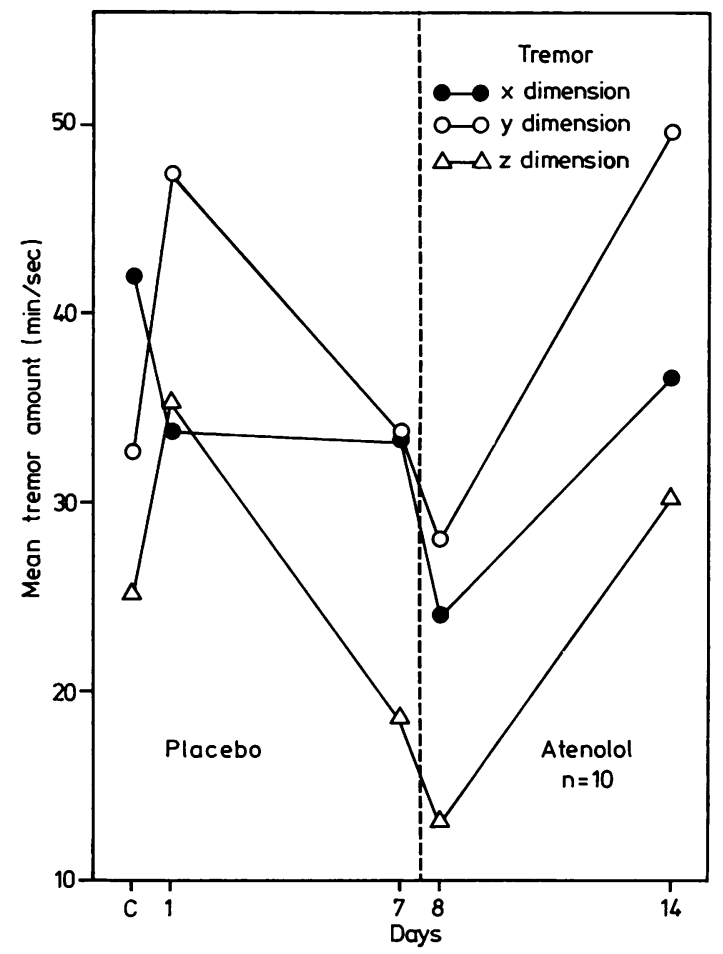

Fig 6 Non-significant tremor reducing effect of atenolol and of placebo.

go, tiredness and a tendency to transient syncope at the beginning of the study.

\section{Discussion}

The present controlled study is based on quantitatively recorded tremor data and shows that timolol in daily $10 \mathrm{mg}$ doses, markedly reduced the tremor amplitude in patients with benign essential tremor. This effect occurred even after two doses, each of $5 \mathrm{mg}$. The effect of the present modest timolol dosage is in subjective judgement, equivalent to that of propranolol, which until now has been our routine medication in amounts from 40-160 mg daily administered in three single doses.

Timolol and propranolol have interesting pharmacokinetic differences. Firstly, propranolol possesses a membrane stabilising ("quinidine-like") effect whereas timolol is devoid of this property. Considering the effect that both these drugs have on essential tremor, it is likely that this effect is unrelated to a membrane stablising action but is due to $\beta$-adrenoreceptor antagonistic properties. 


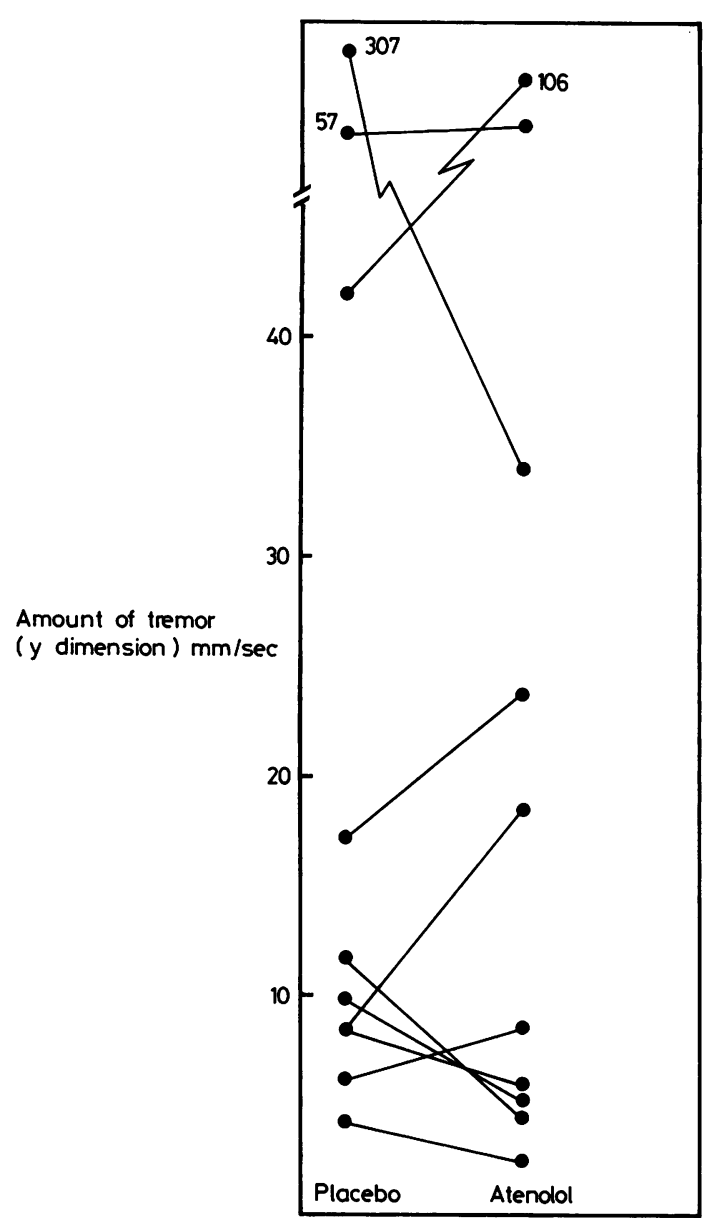

Fig 7 Individual effect on tremor by one dose of atenolol $100 \mathrm{mg}$ as compared to one dose of placebo both taken two hours before the assessment.

Secondly, propranolol is more lipid soluble than timolol. The latter drug should, therefore, have relatively poorer penetration of the blood-brain barrier. Thus, penetration into the central nervous system, may not be important for the therapeutic action of timolol which might exert its effect peripherally.

Atenolol in the present study failed to produce a significant reduction in the amount of tremor, in spite of causing a satisfactory $\beta$-blockade as shown by a similar reduction in heart rate and blood pressure as timolol. This result agrees with that of other workers ${ }^{8}$ who found that atenolol was no better than placebo in reducing tremor as judged by the patients' subjective tremor score, and further, that atenolol was less effective than propranolol in reducing tremor in objective tremor scores. Atenolol also penetrates poorly into the brain. ${ }^{13}$ However, the reason why atenolol fails to control essential tremor seems not to be its relative water solubility, as atenolol shares this property with the tremor-reducing timolol. Another possible explanation of the ineffectiveness of atenolol in reducing tremor, may be that it is a predominantly $\beta 1$-receptor antagonist. ${ }^{14}$

Studies with another beta-adrenoreceptor antagonist metoprolol (Seloken), has made it likely that the absence of a reduction in tremor might be due to lack of $\beta 2$-blocking properties. Thus it has been found in a study of drug-induced tremor in humans, ${ }^{15}$ that metoprolol, which predominantly blocks $\beta 1$ receptors, had no anti-tremor effect, whereas the $\beta 1$ and $\beta 2$ blocking properties of propranolol, had this effect. Some other clinical reports, however, suggest that metoprolol may be of clinical value in tremor treatment. Many authors have reported ${ }^{16-19}$ on individual patients, some being intolerant to propranolol, whose essential tremor responded to metoprolol which was used in higher doses than atenolol in the present study. In 19 of 22 patients with essential tremor, a favourable effect by high doses of metoprolol, has been reported. ${ }^{20}$ The apparent beneficial effect of metoprolol does not, however, establish whether the $\beta$-adrenoreceptors involved in its action are of the $\beta 1$ or $\beta 2$ type. ${ }^{21}$ The $\beta 1$ selective action of the drug is relative and at the doses commonly administered, there is invariably some block of the $\beta 2$ adrenoreceptors.

In the present study, essential tremor was reduced but not blocked by the beta-adrenoreceptor antagonist timolol exerting both $\beta 1$ and $\beta 2$ blocking properties, but not by the predominantly $\beta 1$ blocking drug atenolol. The reduction of tremor amplitude by the water soluble timolol, is apparently not related to its poor penetration into the brain. These findings suggest an important peripheral $\beta 2$ mechanism which determines the amplitude of essential tremor. However, another possibility is that the reduction of tremor, is the result of some active metabolite of the drug and not to the drug itself.

The help of Dr Geoffrey Rushworth, Oxford University, Department of Clinical Neurology, Unit of Clinical Physiology, Radcliffe Infirmary Oxford is gratefully acknowledged in improving the quality of the English. 


\section{References}

1 Winkler GF, Young RR. The control of essential tremor by propranolol. Trans Am Neurol Assoc 1971; 96:66-7.

2 Gilligan BS, Veale JL, Wodak J. Propranolol in the treatment of tremor. Med $J$ Austr I, 1972; 320-2.

3 Sevitt I. A comparison of propranolol and benzhexol in essential tremor. Practitioner 1974; 213: 91-6.

4 Tolosa ES, Loewenson Ruth B. Essential tremor: treatment with propranolol. Neurology (Minneap) 1975; 25:1041-4.

5 Young RR, Growdon JH, Shahani BT. Betaadrenergic mechanisms in action tremor. $N$ Engl J Med 1975; 293:950-3.

6 Jefferson D, Jenner P, Marsden CD. Relationship between plasma propranolol concentration and relief of essential tremor. J Neurol Neurosurg Psychiatry 1979a; 42:831-7.

7 Dietrichson $\mathbf{P}$, Stensrud $\mathbf{P}$. Behandling av benign essensiell tremor med propranolol. Tidskr Nor Lageforen 1976; 96:1436-8.

8 Jefferson D, Jenner P, Marsden CD. Beta-adrenoreceptor antagonists in essential tremor. $J$ Neurol Neurosurg Psychiatry 1979b; 42:904-9.

9 Birmingham AT, Roland J, Heather Wharrad J, Williams EJ, Wilson CG. Effects of atenolol and propranolol on finger tremor in man. Proc $\mathrm{Br}$ Pharmacol Soc 1981; 72:134P.

10 Dietrichson P, Engebretsen $\varnothing$, Fønstelien E,
Hovland J. Quantitation of tremor in man. In: Desmedt JE, ed. Progress in clinical neurophysiology, vol 5. Basel: Karger 1978; 90-4.

11 Gold B, Rader CM. Digital processing of signals. New York: McGraw-Hill 1969.

12 Wilcoxon F, Katti SK, Wilcox RA. Critical values and probability levels for the Wilcoxon rank sum test and the Wilcoxon signed rank test. Tallahassee: Amercian Cyanamid $\mathrm{Co}$ and the Florida State University 1963.

13 Van Swieten PA, Timmermans PBMWM. Comparison between the acute hemodynamic effects and brain penetration of atenolol and metoprolol. J Cardiovasc Pharmacol 1979; 1:85-96.

14 Vilsvik JS, Schaaning J. The effect of atenolol on ventilatory and cardiac function in asthma. $\mathrm{Br}$ Med J 1976; 2:453-5.

15 Larsson S, Svedmyr N. Studies of muscle tremor induced by beta-adrenostimulating drugs. Scand J Respir Dis, suppl 1974; 88:54.

16 Britt CW, Peters BH. Metoprolol for essential tremor. N Engl J Med 1979; 301:331.

17 Riley T, Pleet AB. Metoprolol tartrate for essential tremor. $N$ Engl J Med 1979; 301:663.

18 Turnbull DM, Shaw DA. Metoprolol in essential tremor. Lancet 1980; 95.

19 Newman R, Jacobs L. Metoprolol in essential tremor. Arch Neurol 1980; 37:596-7.

20 Ljung $O$. Treatment of essential tremor with metoprolol. N Engl J Med 1979; 301:1005.

21 Jefferson D, Marsden CD. Metoprolol in essential tremor: Lancet 1980; 427. 